\title{
Effect of Ultrasonic Impact on the Microstructure of Welded Joint of 2195 Al-Li Alloy
}

\author{
Qi-Hao Chen ${ }^{1}$ San-Bao Lin $^{1} \cdot$ Chun-Li Yang ${ }^{1} \cdot$ Cheng-Lei Fan ${ }^{1}$
}

Received: 9 November 2015/Revised: 14 December 2015/Published online: 25 March 2016

(C) The Chinese Society for Metals and Springer-Verlag Berlin Heidelberg 2016

\begin{abstract}
It is known that an ultrasonic impact during tungsten inert gas welding can refine the grains and improve the mechanical properties of the welded joints of aluminum alloys. However, the influence mechanism of the ultrasonic impact on the microstructures is still unclear. In this research, the effects of the mechanical and ultrasonic impact on the microstructures of the welded joint of $2195 \mathrm{Al}-\mathrm{Li}$ alloy are analyzed. It is found that the mechanical impact could not refine the grains, but the ultrasonic impact could refine the grains. The grains become smaller in the weld center with an increase in the ultrasonic amplitude. Possible mechanisms for the grain refinement are discussed. The results show that the small temperature gradient promotes formation of the equiaxed grain and the cavitation promotes heterogeneous nucleation.
\end{abstract}

KEY WORDS: Ultrasound; TIG welding; Microstructure; Al-Li alloy

\section{Introduction}

Al-Li alloys exhibit some excellent properties such as low density, high elastic modulus, high specific strength and stiffness, and excellent corrosion resistance. Therefore, Al$\mathrm{Li}$ alloys are considered to be an important structural material in the aerospace field [1].

Tungsten inert gas (TIG) welding is one of the commonly used fusion welding processes. In general, the conventional TIG-welded joint of Al-Li alloy possesses low strength owing to the existence of coarse microstructures and pores. The application of the Al-Li alloy is limited by the low strength of the welded joint.

Ultrasonic treatment (UST) has received particular attention for nearly 80 years as a potential means to induce

Available online at http://link.springer.com/journal/40195

Chun-Li Yang

yangc19@hit.edu.cn

1 State Key Laboratory of Advanced Welding and Joining, Harbin Institute of Technology, Harbin 150001, PR China grain refinement in the cast field. A comparative study on the microstructure of $\mathrm{Al}-\mathrm{Sn}-\mathrm{Cu}$ immiscible alloys indicates the high effectiveness of the ultrasound in promoting significantly refined microstructure [2]. The effect of highenergy ultrasonic field on the microstructure and mechanical properties of A356 alloy shows that the long dendritic silicon phases are broken into pieces and that the morphology of $\alpha-\mathrm{Al}$ phase presents an approximate ball shape [3]. The influence of power ultrasound on the solidification structure of 7050 aluminum alloy ingot in semi-continuous casting also shows that the solidification structure of the ingot is homogeneously distribution and its grain size is obviously refined at an ultrasonic power of $240 \mathrm{~W}$ [4]. Regarding the mechanism of the grain refinement, there are two interpretations. Puga et al. [5] showed that an increase in the nucleation rate could result in the grain refinement when UST was implemented. However, Qian et al. [6] claimed that cavitation-induced dendrite fragmentation could induce the grain refinement.

Owing to the excellent effect of UST on the grain refinement in the casting field, many scholars have tried to apply UST in the course of welding. The ultrasonic wave is excited successfully by a method involving a high- 
frequency current that modulates a plasma arc. The experimental study of the welding structure indicates grain refinement [7]. TIG welding torch is connected to the ultrasonic transducer and the ultrasonic radiator, and ultrasonic vibrations are applied to the weld arc during the welding process. The direction of ultrasonic vibration was coaxial to the welding electrode [8]. Dai [9] fixed the ultrasonic horn to the surface of aluminum alloy 7075-T6 during TIG welding so that the high-intensity ultrasonic wave is conducted into the aluminum alloy 7075-T6. All of these results suggest that the microstructures of the welded joint are refined after the UST application. Although these ultrasonic-assisted welding techniques could be used to refine the microstructures of the welded joints, some issues restrict their application. The attenuation of the ultrasonic vibration is more serious when propagating through the arc, so a higher ultrasonic power must be used to make more ultrasonic energy into the weld pool.

To resolve this issue, a new welding technique, in which the ultrasonic horn periodically impacts the seam during the TIG welding process such that the ultrasonic vibration effectively influences the crystallization of the weld pool, is adopted. In this method, the distance between the ultrasonic input position and the weld pool remains constant [10]. The experimental results suggest that the microstructure and the mechanical properties of the welded joints of aluminum alloys were improved. However, the mechanism of the grain refinement is still unclear. The influence of the ultrasonic impact on the microstructure of the welded joints of aluminum alloys is investigated in this study.

\section{Experimental procedures}

A schematic of the setup is shown in Fig. 1. The experimental setup consisted of a TIG welding system, a CSHJ2000 US power supply unit developed by CSIC 726, a high-power ultrasonic transducer $(2200 \mathrm{~W})$, and an ultrasonic horn made of $\mathrm{Cr}_{12} \mathrm{MoV}$. This ultrasonic horn, which

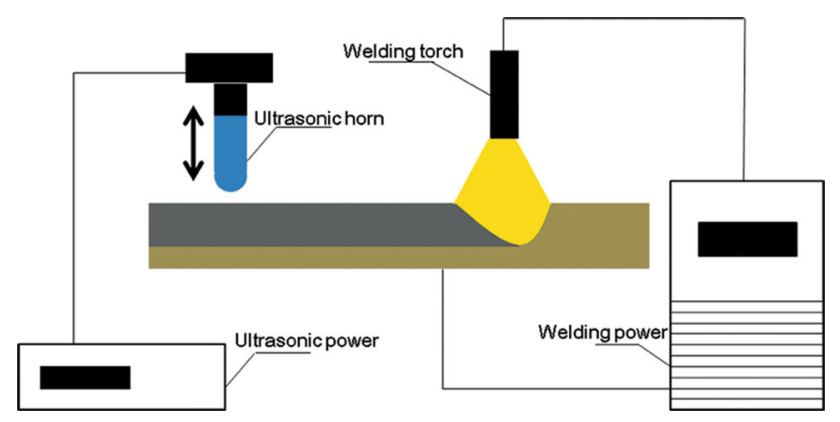

Fig. 1 Schematic of the experimental setup produced $20-\mathrm{kHz}$ vibrations, could impact the workpiece with a constant distance between the impact position and the weld pool. The amplitude of the ultrasonic horn could be adjusted by regulating the ultrasonic power, and three different amplitudes could be obtained. The amplitude was 7.5, 8.10, and $8.81 \mu \mathrm{m}$, respectively. The Miller Dynasty $350 \mathrm{AC} / \mathrm{DC}$ invert welder was used to conduct the welding experiments.

The ultrasonic impact contains two aspects of influence. One is the effect of the UST, and another is the effect of the mechanical impact. To investigate the effects of the mechanical impact and UST on the microstructures of the welded joint, a bead welding experiment on 2-mm-thick sheets composed of the 2195 Al-Li alloy was performed. The surfaces of the cross section and longitudinal section of the welded joint were ground, polished, and chemically etched. The areas of interest were observed under an optical microscope.

In this research, the effects of mechanical and ultrasonic impact on the grain refinement of the welded joints were investigated. The oxide film of the $2195 \mathrm{Al}-\mathrm{Li}$ alloy was removed by mechanical abrasion before welding. The parameters of the welding power source are shown in Table 1. These parameters include: welding current amplitude in alternating current electrode negative duration (EN), welding current amplitude in alternating current electrode positive duration (EP), duty cycle, and frequency. Other parameters were as follows: The output flow rate of the shielding gas was $15 \mathrm{~L} / \mathrm{min}$, the welding speed was $162 \mathrm{~mm} / \mathrm{min}$, the arc length was $3 \mathrm{~mm}$, and the impact frequency was $2.5 \mathrm{~Hz}$.

The microstructure of the welded joint is improved, and the mechanism is investigated. The 1060 aluminum alloy contains few alloy elements, and its crystallization is mainly affected by the temperature distribution in the weld pool. The ultrasonic impact could increase the fluidity of weld pool and then affect the distribution of temperature. Thus, the 1010 aluminum alloy is chosen to investigate the effect of fluidity of the weld pool on the grain refinement of the welded joint. The chemical compositions of 1060 aluminum alloy and 2195 Al-Li alloy are shown in Table 2. Finally, the effect of ultrasonic cavitation on nucleation rate is also analyzed.

Table 1 Parameters of the welding power source

\begin{tabular}{llll}
\hline EN $(\mathrm{A})$ & EP $(\mathrm{A})$ & Duty cycle $(\%)$ & Frequency $(\mathrm{Hz})$ \\
\hline 100 & 53 & 75 & 100 \\
\hline
\end{tabular}


Table 2 Chemical compositions of $2195 \mathrm{Al}-\mathrm{Li}$ alloy and 1060 aluminum alloy (wt\%)

\begin{tabular}{llllllllllllll}
\hline Material & $\mathrm{Cu}$ & $\mathrm{Li}$ & $\mathrm{Ag}$ & $\mathrm{Zr}$ & $\mathrm{Ti}$ & $\mathrm{Fe}$ & $\mathrm{Si}$ & $\mathrm{Mn}$ & $\mathrm{V}$ & $\mathrm{Mg}$ & $\mathrm{Zn}$ & $\mathrm{Al}$ \\
\hline 2195 & 4.02 & 1.00 & 0.40 & 0.11 & 0.068 & 0.16 & 0.03 & 0 & 0 & 0 & 0 & $\mathrm{Bal}$. \\
1060 & 0.05 & 0 & 0 & 0 & 0.03 & 0.35 & 0.25 & 0.03 & 0.05 & 0.03 & 0.05 & Bal. \\
\hline
\end{tabular}

\section{Results and Discussion}

\subsection{Influence of Mechanical Impact on Grain Refinement of Welded Joint}

Two aspect effects exist when the ultrasonic horn impacts the workpiece. One is the mechanical impact, and the other is the periodic ultrasonic energy. It is unclear which effect results in the grain refinement of the welded joints. To investigate the reason for grain refinement of the welded joint following an ultrasonic impact, welding experiments without wire feeding were conducted. The effects of the mechanical and ultrasonic impact on the microstructure of the welded joint were investigated. The microstructures of cross section of the welded joints are shown in Fig. 2.

The results show that the coarse columnar dendrite exists around the fusion zone for the original TIG-welded joint and the joint with the mechanical impact. The columnar grain becomes an equiaxed grain around the fusion zone when the ultrasonic energy exists, suggesting that the mechanical impact does not provide a favorable effect on the grain refinement, but the ultrasonic energy is effective for the grain refinement of welded joints of 2195 Al-Li alloy.

\subsection{Influence of the Ultrasonic Amplitude on the Grain Refinement of the Welded Joint}

The ultrasonic energy results in the grain refinement of the welded joints according to the previous analysis. How does the ultrasonic energy affect the grain refinement? That is investigated in this section. The change in the microstructure in the fusion zone is not obvious, so the microstructure of the weld center is shown in Fig. 3. The results show that the grain becomes smaller and smaller with increasing the ultrasonic amplitude. The grain size is uniform when the ultrasonic amplitude is $8.81 \mu \mathrm{m}$. The color is different from other two pictures in Fig. 3a because the chemical etched is more significant for the sample. For the relation between the microstructure and the ultrasonic power, Cui et al. [11] investigated the relation between the columnar dendritic microstructure and the power of the ultrasonic vibration welding in AISI 304 stainless steel. Their results suggest that an increase from $0 \%$ to $90 \%$ in the ultrasonic power vibration system results in a $95 \%$ $10 \%$ decrease in the fraction of the columnar dendritic microstructure, giving rise to a predominantly thin microstructure of the dendritic equiaxed grain. The ultrasonic energy increases when the ultrasonic amplitude increases. The effect of the ultrasound on the crystallization of weld pool increases when the ultrasonic energy increases in the weld pool.

\subsection{Discussion of Mechanism for the Grain Refinement}

The fluidity of the melt increases when the ultrasound propagates into the melt due to acoustic streaming [12]. Thus, the fluidity of the weld pool increases when applying the ultrasonic impact, and the change in the fluidity of the weld pool could affect the heat transfer. The alloy element is rare for the 1060 aluminum alloy, and the solidification of 1060 commercially pure aluminum is mainly affected by
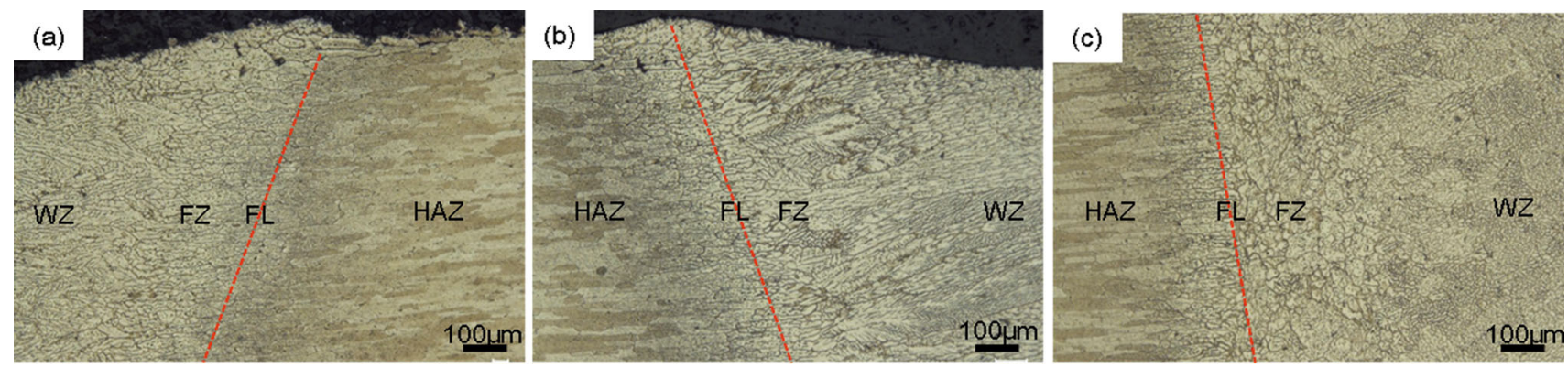

Fig. 2 Microstructures of the welded joint: a original TIG, b mechanical impact, and $\mathbf{c}$ ultrasonic impact 

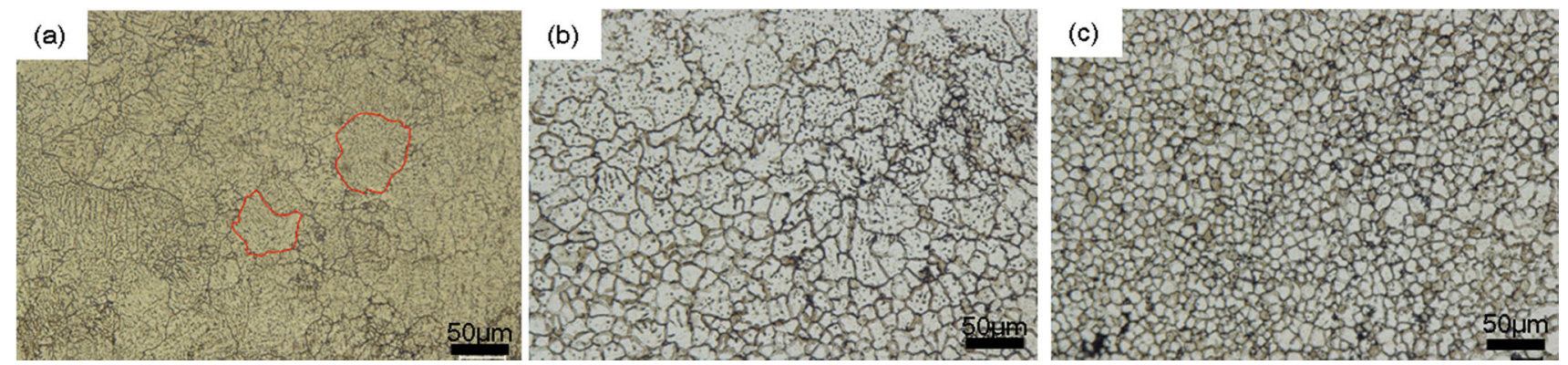

Fig. 3 Effect of the ultrasonic amplitude on the grain refinement in the weld center a $7.5 \mu \mathrm{m}, \mathbf{b} 8.1 \mu \mathrm{m}$, and $\mathbf{c} 8.81 \mu \mathrm{m}$

the temperature inside weld pool. Thus, the welding of 1060 commercially pure aluminum was conducted to investigate the effect of the fluidity of the weld pool on the grain refinement. The microstructure of the cross section of the welded joint is shown in Fig. 4. The results suggest that the size of the grain is smaller and becomes more uniform in the weld center, and the grain changes from a columnar grain to an equiaxed grain in the fusion zone after applying the ultrasonic impact.

The ultrasound could reduce the temperature nonhomogeneity of the melt and help to homogenize the melt temperature during casting according to $\mathrm{Li}$ et al. [13].
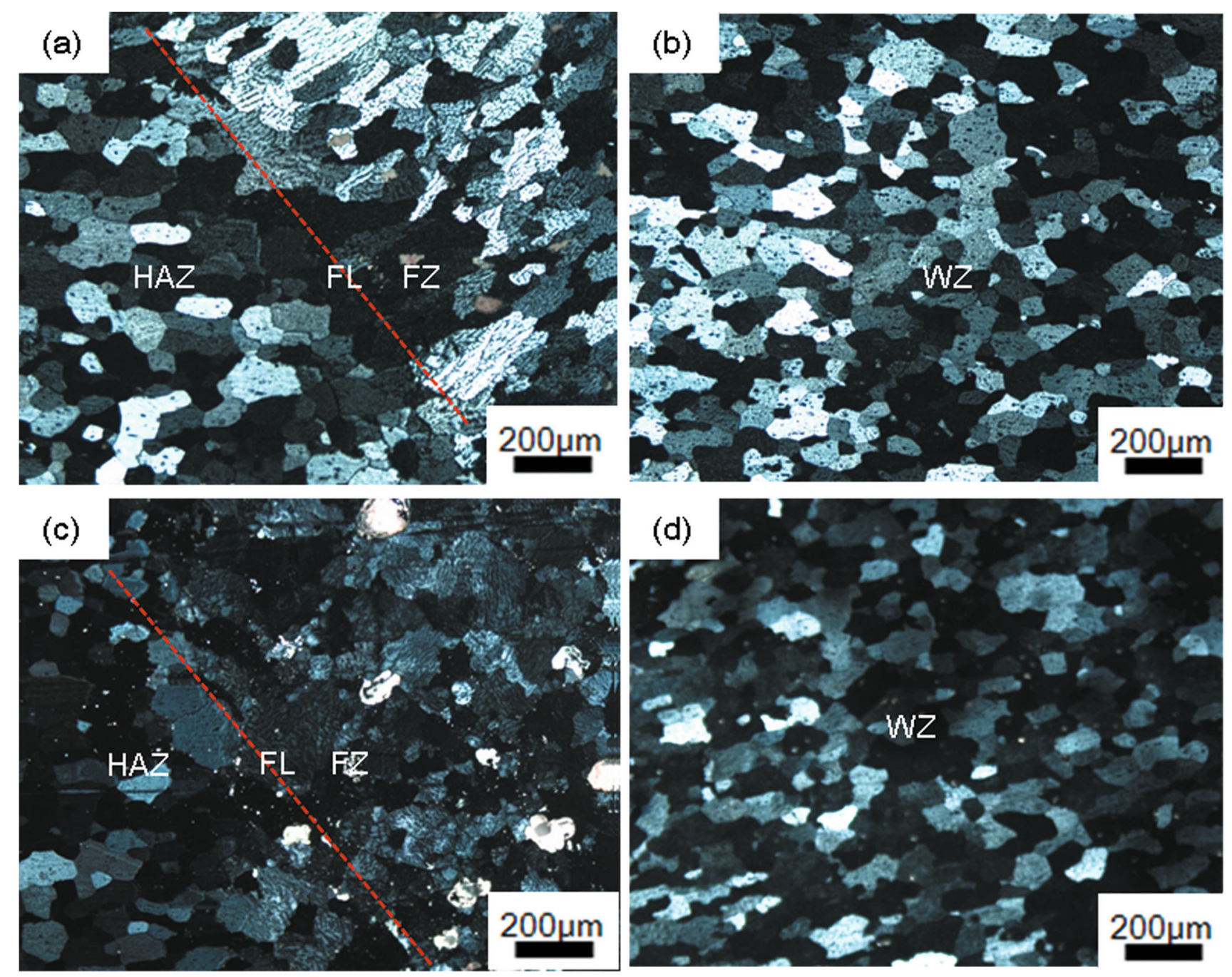

Fig. 4 Macrostructures observed by optical microscopy (OM) at the a fusion zone without the ultrasonic impact, b weld center without the ultrasonic impact, $\mathbf{c}$ fusion zone with the ultrasonic impact, $\mathbf{d}$ weld center with the ultrasonic impact 


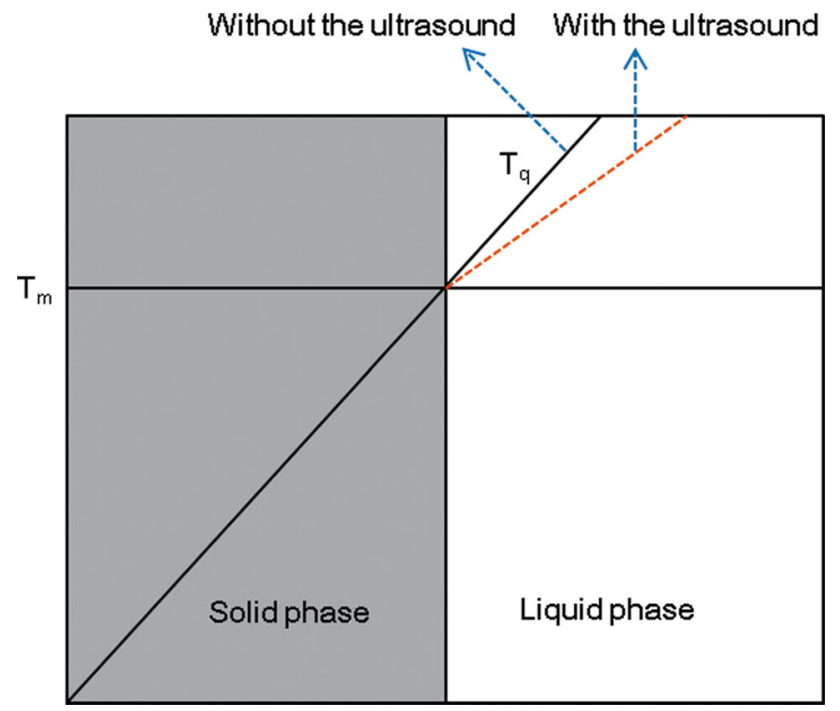

Fig. 5 Temperature distribution in the weld pool

Thus, the temperature gradient declined and the temperature became homogeneous in the weld pool. Figure 5 shows the effect of ultrasonic energy on the temperature gradient of the weld pool. $T_{\mathrm{m}}$ represents the melting point, and $T_{\mathrm{q}}$ represents the temperature of the melt. According to previous analysis, the grain is the columnar grain before UST in the fusion zone. However, the columnar grain disappears after applying the UST. This is because the temperature gradient declines in the fusion zone and in the weld center. The change in the temperature gradient of the weld pool restricts the growth of columnar grain and promotes the growth of equiaxed grain.

The microstructure of the longitudinal section of the welded joint of $2195 \mathrm{Al}-\mathrm{Li}$ alloy was also analyzed. The UST time is $0.2 \mathrm{~s}$, and the interval time is $0.2 \mathrm{~s}$ for one ultrasonic impact cycle. Zone 1 is the region where the ultrasonic vibrations exist during solidification. Zone 2 is the region where the ultrasonic vibrations exist before solidification and the ultrasonic vibration is ceased during solidification. According to the fact that the embossment appears when the ultrasonic impact exists and the embossment disappears when the ultrasonic impact is ceased, the zone 1 and zone 2 could be specified as shown in Fig. 6.

The results show that the grains in zone 2 are also refined, and they are smaller than those in the zone 1 . This suggests that the ultrasound can also refine the grains when the ultrasonic impact is implemented before solidification. According to previous research [14], numerous particles

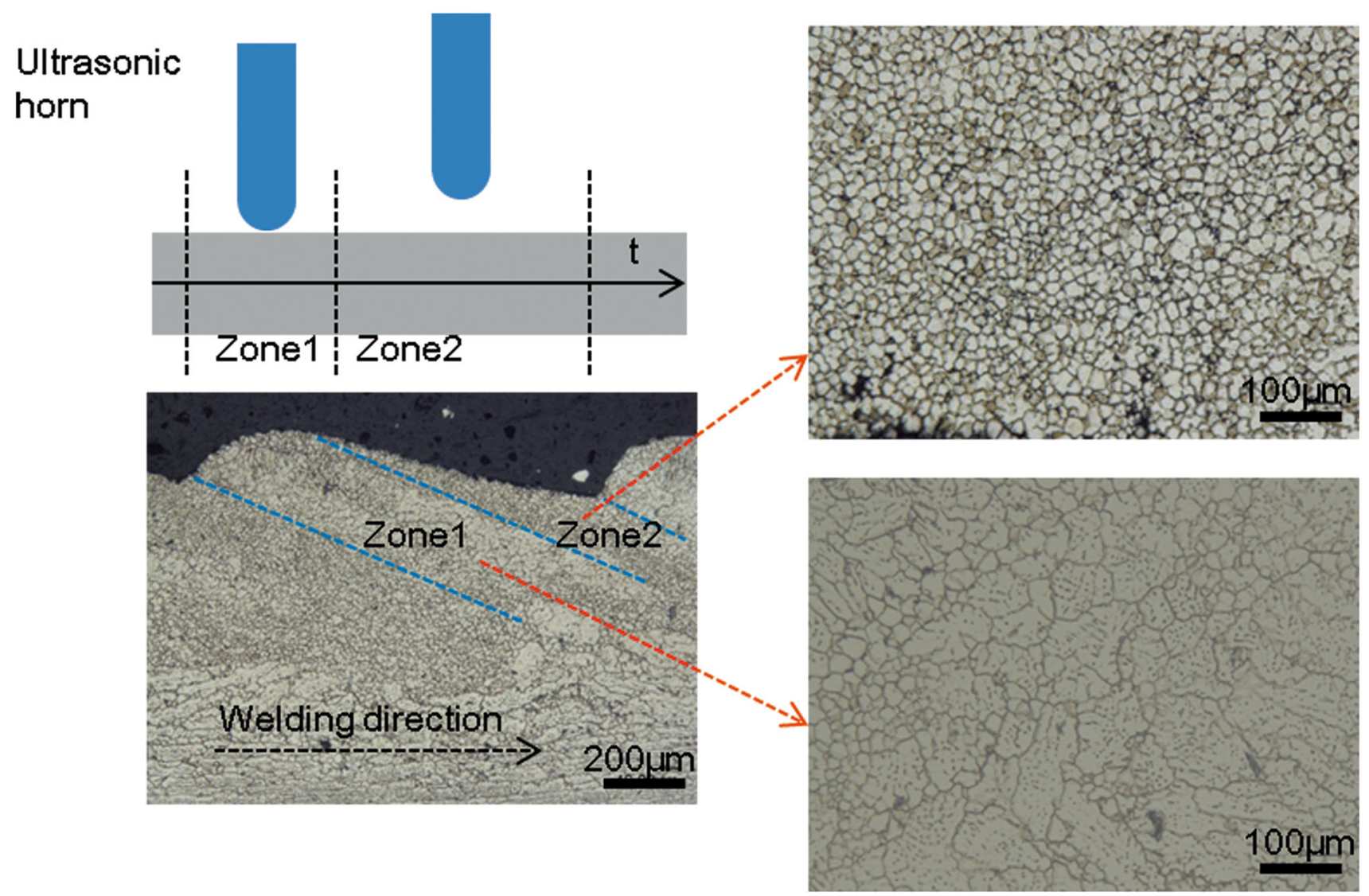

Fig. 6 Microstructures of a longitudinal section 
with a high melting point exist in the melt of the cast, and these particles could serve as the heterogeneous nucleation sites. The heterogeneous nucleation rate could be increased when the ultrasound treats the melt. Atamanenko et al. [15] found that small additions of zirconium and titanium can significantly increase the efficiency of UST, which also proved that the nucleation rate could be increased by the ultrasonic melt treatment. Heterogeneous nucleation during UST of a melt can occur by (1) activation of high-temperature-stable particles by cavitation $[16,17]$ and (2) undercooling of the melt by cavitation [18]. Numerous particles with a high melting point also exist in the weld pool, so the heterogeneous nucleation rate could also be increased when the ultrasonic impact is implemented before solidification.

\section{Conclusions}

1. The mechanical impact is not effective for the grain refinement, but the ultrasonic energy is effective for the grain refinement of the welded joint of the 2195 Al-Li alloy.

2. The grains in the weld center and the fusion zone are refined, and in the fusion zone, the grains change from a columnar grain to an equiaxed grain after the UST.

3. The ultrasonic energy decreases the temperature gradient in the weld pool. The columnar grains are restrained, and the equiaxed grains are promoted.

4. The grain could be refined by the UST before solidification of weld pool.
Acknowledgments This project was supported by the Key Program of the National Natural Science Foundation of China (Grant No. 51435004).

\section{References}

[1] A.E. Hughes, R.J. Taylor, B.R.W. Hinton, Surf. Interface Anal. 25, 223 (1997)

[2] H.R. Kotadia, A. Das, E. Doernberg, R. Schmid-Fetzer, Mater. Chem. Phys. 131, 241 (2011)

[3] S.L. Zhang, Y.T. Zhao, X.N. Cheng, G. Chen, Q.X. Dai, J. Alloys Compd. 470, 168 (2009)

[4] L.H. Zhang, Y. Jun, X.M. Zhang, J. Cent, South Univ. Technol. 17, 431 (2010)

[5] H. Puga, S. Costa, J. Barbos, S. Ribeiro, M. Prokic, J. Mater. Process. Technol. 211, 1729 (2011)

[6] M. Qian, A. Ramirez, A. Das, J. Cryst. Growth 311, 3708 (2009)

[7] L.B. He, P. Yang, L.M. Li, M.S. Wu, Ultrasonics 54, 2178 (2014)

[8] Q.J. Sun, S.B. Lin, C.L. Yang, G.Q. Zhao, Sci. Technol. Weld. Join. 14, 765 (2009)

[9] W.L. Dai, Mater. Lett. 57, 2447 (2003)

[10] H.T. Qu, M.E. thesis, Harbin Institute of Technology, 2014 (in Chinese)

[11] Y. Cui, C.L. Xu, Q. Han, Adv. Eng. Mater. 9, 161 (2007)

[12] L. Nastac, ISIJ Int. 54, 1830 (2014)

[13] J.W. Li, T. Momono, Y. Fu, J. Zheng, Y. Tayu, Trans. Nonferrous Met. Soc. China 17, 691 (2007)

[14] A. Ramirez, Q. Ma, B. Davis, T. Wilks, D.H. Stjohn, Scr. Mater. 59, 19 (2008)

[15] T.V. Atamanenko, D.G. Eskin, L. Zhang, L. Katgerman, Metall. Mater. Trans. A 41, 2056 (2010)

[16] G.I. Eskin, Ultrasonic Treatment of Light Alloy Melts (Gordon and Breach Science Publishers, Amsterdam, 1998)

[17] Y. Tsunekawa, H. Suzuki, Y. Genma, Mater. Des. 22, 467 (2001)

[18] G. Wang, M.S. Dargusch, M. Qian, D.G. Eskin, D.H. Stjohn, J. Cryst. Growth 408, 119 (2014) 